\title{
GSPAC water movement in extremely dry area
}

\author{
HongShou $\mathrm{LI}^{1,2^{*}}$, WanFu WANG ${ }^{1,2}$, GuoBin ZHANG ${ }^{1,2}$, ZhengMo ZHANG ${ }^{1,2}$, XiaoWei WANG ${ }^{1,2}$ \\ ${ }^{1}$ The Conservation Institute of Dunhuang Academy, Dunhuang 736200, China; \\ ${ }^{2}$ Key Scientific Research Base of Conservation for Ancient Mural State Administration for Cultural Heritage, Dunhuang 736200 , \\ China
}

\begin{abstract}
Under an extremely arid condition, a PVC greenhouse was built on the top of Mogao Grottoes in gobi area. The results of 235-day constant extraction of condensed water on the greenhouse film and soil water content showed that $2.1 \mathrm{~g} /\left(\mathrm{m}^{2} \cdot \mathrm{d}\right)$ groundwater moved up and exported into the soil, and a phreatic water evaporation existed in the extreme dry area where the groundwater is buried deeper than $200 \mathrm{~m}$. After a prolonged export, the soil water content in the greenhouse was not lower but obviously higher than the original control ones. According to the monitored parameters including relative humidity and absolute humidity of soil, and temperature outside and inside the greenhouse, it was found that there is the available condition and mechanism for the upward movement of groundwater, and also it can be sure that the exported water was not from the soil and atmosphere outside the greenhouse. Phreatic water, an important source for soil water, interacts with atmosphere moisture via soil respiration. Soil salinity also has important effects on soil water movement and spatial-temporal heterogeneity. The extremely dry climate, terrestrial heat and change of upper soil temperature are the fundamental driving forces of water transportation and phreatic water evaporation in the Groundwater-Soil-Plant-Atmosphere Continuum (GSPAC) system.
\end{abstract}

Keywords: greenhouse method; GSPAC system; extremely dry area; water movement

\section{Introduction}

Water circle is important to ecosystem. Vertical water circle is constituted by the water movement in the Ground water-Soil-Plant-Atmosphere Continuum (GSPAC) system (Wang et al., 2004; Zhou et al., 2005). It is well known that when groundwater level is shallow, phreatic water is an important supplement to soil, plant and atmosphere moisture through capillary action (Yang, 1999; Chen et al., 2004; Ren et al., 2006). However, it remains unclear whether phreatic water can contribute to soil water, which is a key to understand whether there is a maximum depth of phreatic water evaporation (Zhu and Qian, 2005).

A common belief is that soil water in extremely dry area is the remain of last precipitation (Warner, 2008). However, Liu et al. (2006) found that precipitation is invalid if its amount is less than or equal to $13.44 \mathrm{~mm}$, because water would be evaporated completely before permeating into deep soil. In former simulated precipitation experiments we found that a rainfall ranging from $5 \mathrm{~mm}$ to $10 \mathrm{~mm}$ could be evaporated entirely within 8 days and 12 days respectively, and a $15 \mathrm{~mm}$ rainfall once-in-a-decade in Mogao Grotteos within 20 days (Li et al., 2010a).

According to previous investigations, the soil water content was high in the proluvial clay layer at $1.4 \mathrm{~m}$ depth of the gobi land around the Grottoes (Li et al., 2009), and it could reach $24 \%$ at $4 \mathrm{~m}$ depth (Yang et al., 2009). Further, the experiments conducted in closed system revealed that the annual precipitation in this area $(42.2 \mathrm{~mm})$ is not enough to supply soil water content (Li et al., 2010a). Therefore, other water resources supplying soil water indeed exist.

The only possible resource of soil water except precipitation is phreatic water. The research work on the climate, geology and vegetation in this area proved the possibility of vertical transportation of phreatic water (Li et al., 2009). However, as the phreatic water in this area is buried deeper than $200 \mathrm{~m}$, water could not be transported upward due to capillary action. To further verify the existence of phreatic water evaporation, a PVC greenhouse was used to eliminate the influence

Received 2010-10-28, accepted 2011-01-06

doi: 10.3724/SP.J.1227.2011.00149

* Corresponding author: HongShou LI (E-mail: dhlhs69@163.com). 
of precipitation and atmosphere (Li et al., 2010a), and the amount of phreatic water evaporation by measuring condensed water on film and soil water content were calculated (Li et al., 2010b). Additionally, small monitors were buried in soil to directly gauge the temperature and relative/absolute humidity. The analysis work on the movement of GSPAC system would provide scientific grounds for the effective utilization of phreatic water in this extremely arid region.

Mogao Grottoes, with nearly $45,000 \mathrm{~m}^{2}$ frescos, is the biggest and most completed Buddhism relic in the world. The frescos are confronted with a series of questions concerning soil water, but it is still unclear where the water comes from ( $\mathrm{Li}, 2005)$. Consequently, the understanding of the water movement in the GSPAC system on the top of Mogao Grottoes will be beneficial to explain water resource in the surrounding rocks of the Grottoes and to protect the precious cultural relic.

\section{Study area}

The greenhouse experiment was carried out in the gobi land, $1 \mathrm{~km}$ to the grottoes, from June 6, 2008 to February 18,2009 . The upper $4 \mathrm{~m}$ layer of the gobi is loose gravel sand, and the lower layer is gravel. The gobi land is formed by Pleistocene diluvia conglomerate, mid-Pleidiluvial alluvial Jiuquan conglomerate $(\mathrm{Li}$, 2005). The geology and water structure of study area are shown in Fig. 1.

The upper $0-50 \mathrm{~cm}$ soil is abundant in salts. The constitution and contents of dissolved salts are shown in Table 1 . The soil porosity is $20 \%$ to $30 \%$. The aridity index is 32 , indicating an extremely arid climate, and the relative humidity is $31 \%$. The radiation intensity is $1.1 \mathrm{KW} / \mathrm{m}^{2}$ and the percent of sunshine is $71 \%$. The annual average temperature is $11.23^{\circ} \mathrm{C}$, wind speed 4.1 $\mathrm{m} / \mathrm{s}$ (in 2005) and annual precipitation $42.2 \mathrm{~mm}$. In 2007, 19 times of rainfall were recorded and the precipitation totaled $64 \mathrm{~mm}$. From the beginning to the end of experiments there were only 5 times of rainfall with a total precipitation of $8.2 \mathrm{~mm}$. Conducted in the year with notably less rainfall, this research on GSPAC water would make it more clear that the prelatic water is a resource of soil water.

\section{Methods}

A hemisphere greenhouse was built at the gobi land above Mogao Grottoes on the $119^{\text {th }}$ day after a $2 \mathrm{~mm}$ precipitation in 2008. The greenhouse is $1.8 \mathrm{~m}$ high

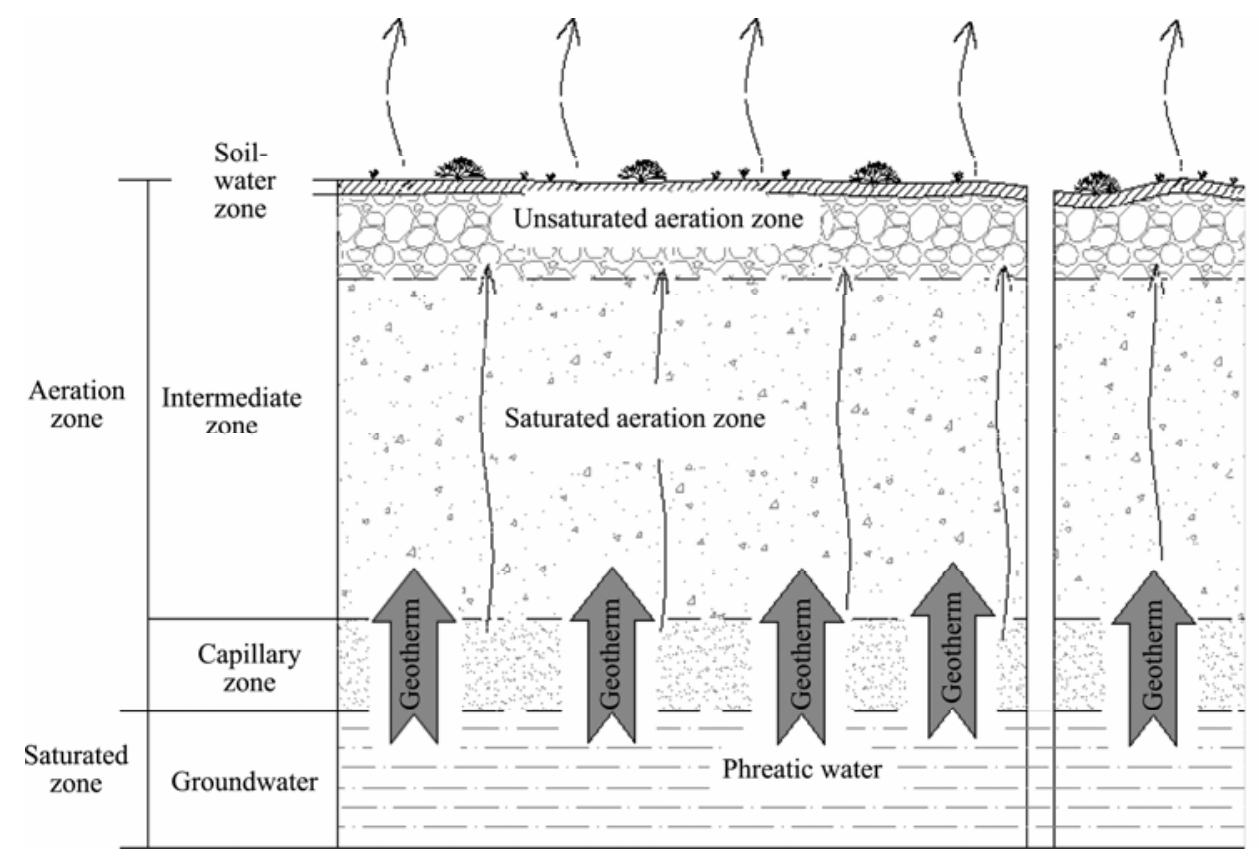

Fig. 1 Sketch of geology and groundwater structure of Mogao Grottoes 
Table 1 Salinity contents in different gobi soil depths at Mogao Grottoes

\begin{tabular}{|c|c|c|c|c|c|c|c|c|c|}
\hline \multirow{2}{*}{$\begin{array}{l}\text { Depth } \\
\text { (cm) }\end{array}$} & \multirow{2}{*}{$\mathrm{pH}$} & Total salt & $\mathrm{NaCl}$ & $\mathrm{Na}_{2} \mathrm{SO}_{4}$ & $\mathrm{CaSO}_{4}$ & $\mathrm{Ca}\left(\mathrm{HCO}_{3}\right)_{2}$ & $\mathrm{KCl}$ & $\mathrm{MgSO}_{4}$ & $\mathrm{CaCO}_{3}$ \\
\hline & & \multicolumn{8}{|c|}{ (\%) } \\
\hline $0-10$ & 8.54 & 9.187 & 5.362 & 1.370 & 1.969 & 0.048 & 0.103 & 0.057 & 0.009 \\
\hline $10-30$ & 8.65 & 4.462 & 0.850 & 2.298 & 1.130 & 0.053 & 0.041 & 0.016 & 0.009 \\
\hline $30-50$ & 8.52 & 2.230 & 0.431 & 0.592 & 1.019 & 0.057 & 0.023 & 0.010 & 0.012 \\
\hline $50-70$ & 8.60 & 1.775 & 0.313 & 0.294 & 1.218 & 0.055 & 0.015 & 0.008 & 0.012 \\
\hline
\end{tabular}

with a radius of $3.1 \mathrm{~m}$, an area of $30 \mathrm{~m}^{2}$ and a volume of $30 \mathrm{~m}^{3}$ (Fig. 2). A plastic belt was bonded to the water-proof film near the ground surface to make a "V" shape groove to collect condensed water. In order to monitor the exportation of soil water inside the greenhouse, an injector was used to extract the condensed water every day at 8 a.m. to 9 a.m. As soil water content is very low in this dry area and moisture is an important form of soil water movement, we adopted HOBO mini-monitors to monitor the temperature, relative and absolute humidity at 5, 10, 20, $30,50,70,100 \mathrm{~cm}$ soil layers beneath and $0,5,10,50$, $100 \mathrm{~cm}$ above ground surface both inside and outside greenhouse as well as on the inner film surface in an interval of 10 minutes. These parameters were utilized to analyze whether water upward movement exists or not. The soil water contents were measured by oven dry method after long-term water exportation. If the measured values are not less than original control ones, it could indicate water resource from deep soil layer indeed exists.

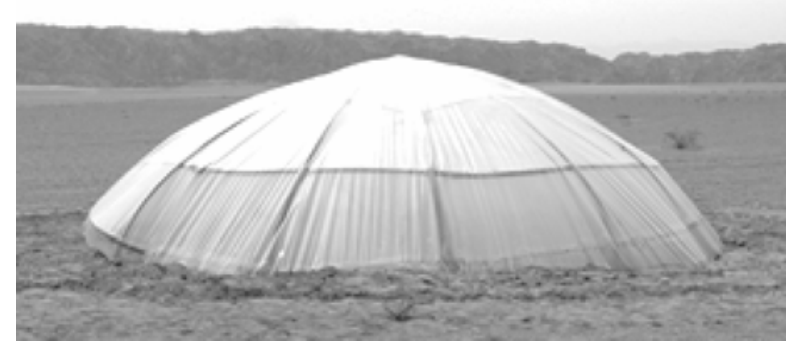

Fig. 2 The PVC greenhouse

\section{Results and discussion}

\subsection{Condensed water in the greenhouse}

The results of this experiment proved the existence of condensed water and constantly upward movement and evaporation of ground water. The daily condensed water amount from July 7 to October 31, 2008 is shown in Fig. 3 with an average daily amount of $84 \mathrm{~g}$, equal to $2.8 \mathrm{~g} /\left(\mathrm{m}^{2} \cdot \mathrm{d}\right)$ soil water exportation. From November 1, 2008 to February 18, 2009, water was freezing and daily monitoring was not available; we collected 2,339 g water and ice at several times, equal to $0.71 \mathrm{~g} /\left(\mathrm{m}^{2} \cdot \mathrm{d}\right)$ soil water exportation. During the 235-day measurement, 15,081 g condensed water was got in total, equal to $2.1 \mathrm{~g} /\left(\mathrm{m}^{2} \cdot \mathrm{d}\right)$ soil water exportation. Condensed water amount is highly related to weather condition. When solar radiation tends to be stronger and temperature becomes higher and daily temperature difference is bigger, the condensed water amount will be higher.

\subsection{Dynamic analysis of temperature-humidity condition and soil water movement}

\subsubsection{Temperature}

Temperature is a main environmental factor influencing soil water evaporation and moisture change. The temperature changes inside and outside greenhouse on typical days during the experimental period are shown in Fig. 4. Within the upper $50 \mathrm{~cm}$ layer, soil temperature changed with solar radiation, and the closer to soil surface, the bigger the varying amplitude of the soil temperature was. No obvious change was shown beneath $50 \mathrm{~cm}$ soil layer. The result indicates that the depth of soil temperature change was lower than 60 $\mathrm{cm}$ even in summer, much lower than the ones of $1-1.5 \mathrm{~m}$ in other regions (Liu and Cai, 2000). The maximum temperature inside the greenhouse was $15^{\circ} \mathrm{C}$ higher in the day and only $1^{\circ} \mathrm{C}$ higher in the night than that of outside. In autumn, the average temperatures at $10,20,30$, and $50 \mathrm{~cm}$ soil layers 


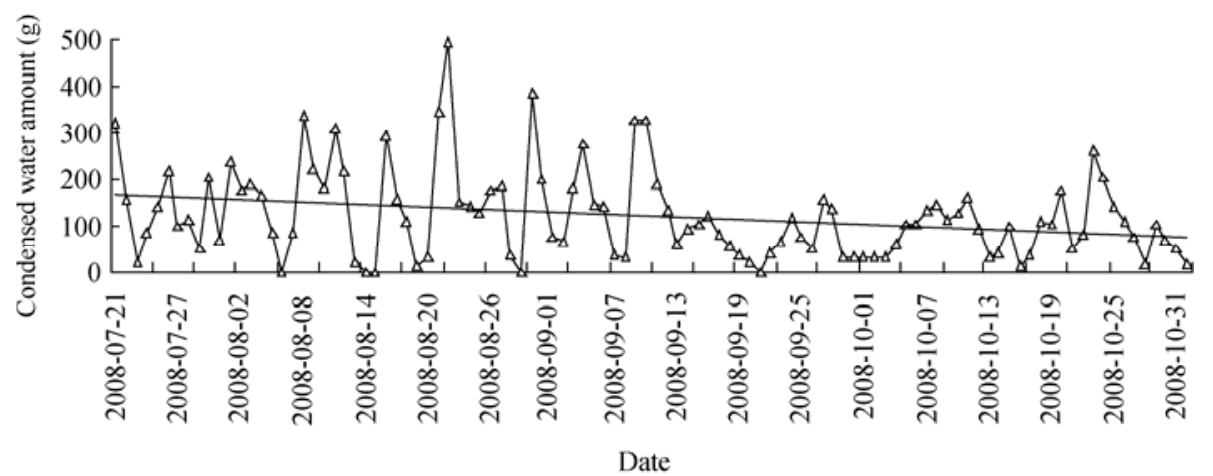

Fig. 3 The daily water condensing amount in the greenhouse
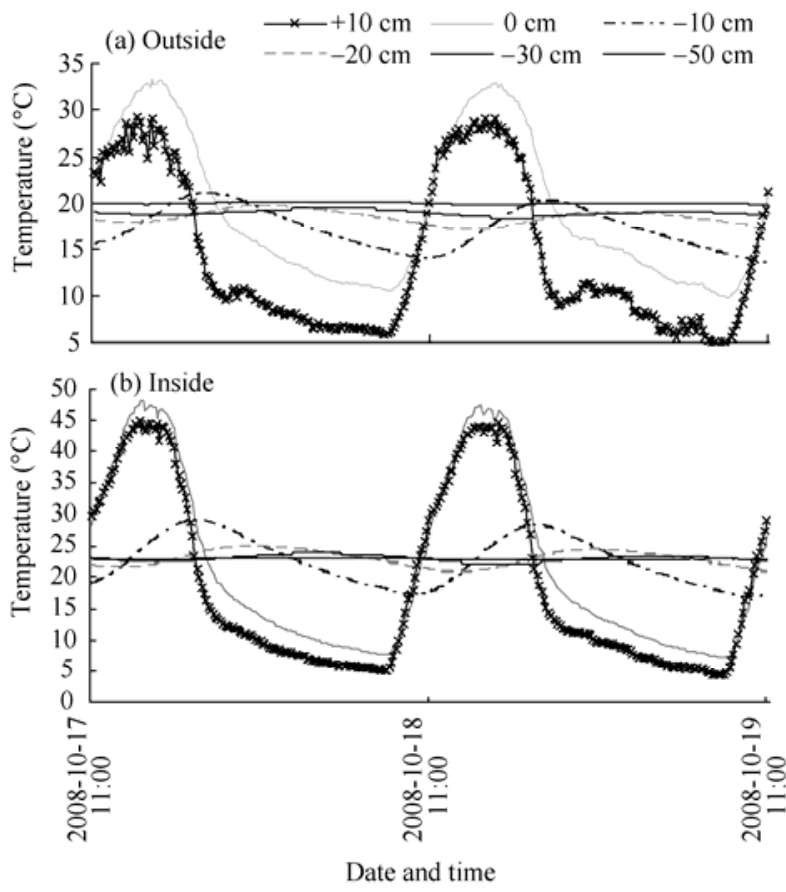

Fig. 4 Temperatures profiles inside and outside the greenhouse

in the greenhouse were $5.2^{\circ} \mathrm{C}, 4.8^{\circ} \mathrm{C}, 4.4^{\circ} \mathrm{C}$, and $3.3^{\circ} \mathrm{C}$ higher than that at control ones outside respectively, while in summer the difference became bigger up to $5-8^{\circ} \mathrm{C}$. The "heat island" of the closed environment in greenhouse greatly impacted the evaporation and horizontal movement of soil water.

In the early days after the construction of the greenhouse, the inner temperature increased whereas the relative humidity declined, thus causing the increase of unsaturated vapour pressure difference and soil water evaporation. According to the daily change of moisture density in this time, the evaporation intensity was estimated at most $0.02 \mathrm{~mm} / \mathrm{d}$. However, the increase of humidity strongly restricted water evaporation on account of the impact of closed environment after three days, which resulted in the decline of correlation between temperature and soil humidity. The correlation between relative humidity and temperature at $20 \mathrm{~cm}$ depth is $0.499(P=0.01)$ in the control soil but only -0.283 inside greenhouse. Therefore, the actual evaporation capacity of gobi soil may be significant in the arid air environment.

As soil water content is always very low in extremely dry area, soil water usually exists as bound water. The decomposition and combination of water coexist in a way of a bi-dynamical balance. When temperature is high, the decomposition amount is bigger than the combination one, reflecting that the increase of soil relative humidity and evaporation. Otherwise, bound water in soil is formed because moisture is adsorbed by soil, which leads to the reduction of vapour pressure and the upward movement of sub-layer soil moisture.

The daily change of soil water content in gobi land under a typical dry weather condition is shown in Fig. 5. Due to the daily change of solar radiation and delay of heat conduction in soil, the temperature in one layer may intersect with that in other layers, which results in the heterogeneous distribution of soil water content with the temperature change. For instance, in Fig. 4 the temperature at $20 \mathrm{~cm}$ depth might be higher or lower than those at any other layers, and the soil water content could show a doublet distribution driven by a higher temperature (e.g. Fig. 5, 17:00). A warming up progress is accompanied with decomposition of bound water, increase of soil humidity and decrease of soil water content, and vice versa. 


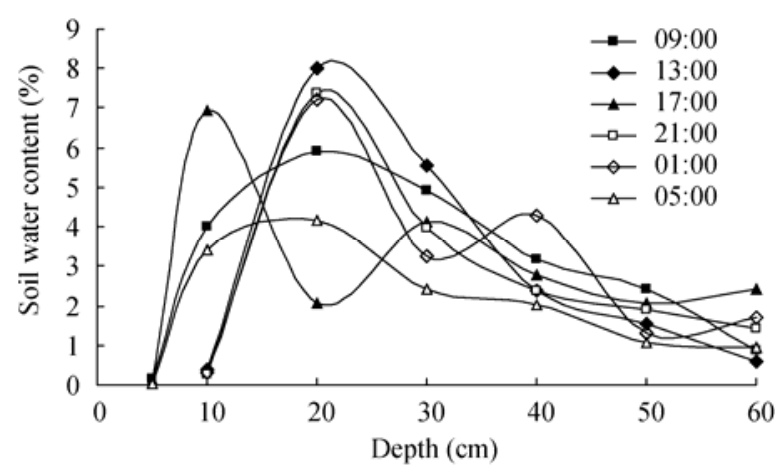

Fig. 5 The daily change of soil water content in the gobi land (2007-06-12)

When soil temperature is high, the decomposed water in upper soil layer could be absorbed by sub-layer soil where temperature is lower, and the rest small amount water evaporates into the air. On the contrary, upper soil layer absorbs water from warmer and wetter sub-layer soil when the temperature is low,and the absorbed amount is farther bigger than that from surface soil and air. Under this thermo-dynamical circumstance of soil water moving upward, the change of vapour pressure plays a critical role (Zhu and Qian, 2005). As shown in Fig. 5, the daily change of the soil water content could amount to 3.8 $\mathrm{mm}$, over 1,000 times compared with the condensed amount in the greenhouse. As a result, the condensed water amount could be only recognized as an evidence of the existence of phreatic soil water evaporation. The upward migration of water needed to be highlighted to further confirm the amount of phreatic water evaporation.

The unsaturated soil water moves from the position with higher temperature/humidity to that with lower ones. The coexistence of higher temperature and humidity is sufficient but not essential to the outer migration of soil water in sub-layer ( Zhu and Qian, 2005; Warner, 2008). In summer, even if the temperature at the top soil is higher, the soil humidity still increases from top to bottom which supports the upward migration of soil water. The condensed water amount in summer is significant when air temperature is high. The decline of condensed water amount in Fig. 3 is due to the decrease of air temperature. Although the soil temperatures at different layers were intersected, the soil water remained upward movement. According to the maximum and minimum absolute humidity (the daily range of vapour density in summer is about 20 $\mathrm{g} / \mathrm{m}^{3}$ and $15 \mathrm{~g} / \mathrm{m}^{3}$ in autumn), only $20 \%$ of evaporated water condensed on film and $80 \%$ was re-absorbed by soil with the decrease of temperature. The absorbing effect of soil moisture from air is so strong that there was no condensed water in the greenhouse in the first 19 days after building it.

\subsubsection{Humidity}

Figure 6 shows the relative and absolute humidity at different heights above ground surface and depths of soil layers in the greenhouse. Closed to underlying surface $(50 \mathrm{~cm})$ the humidity was impacted by moisture of soil absorbing and the relative humidity was lower than that at upper layer $(100 \mathrm{~cm})$ of ground surface. Both the relative and absolute humidity in the soil increased with soil depths. Relative humidity of soil at $20 \mathrm{~cm}$ depth increased with temperature $(r=$ $0.286, P=0.01$ ), while at $50 \mathrm{~cm}$ above surface it was opposite $(r=0.969, P=0.01)$. Soil bound water decomposed when the temperature increased and resulted in high soil humidity. Otherwise, it would be

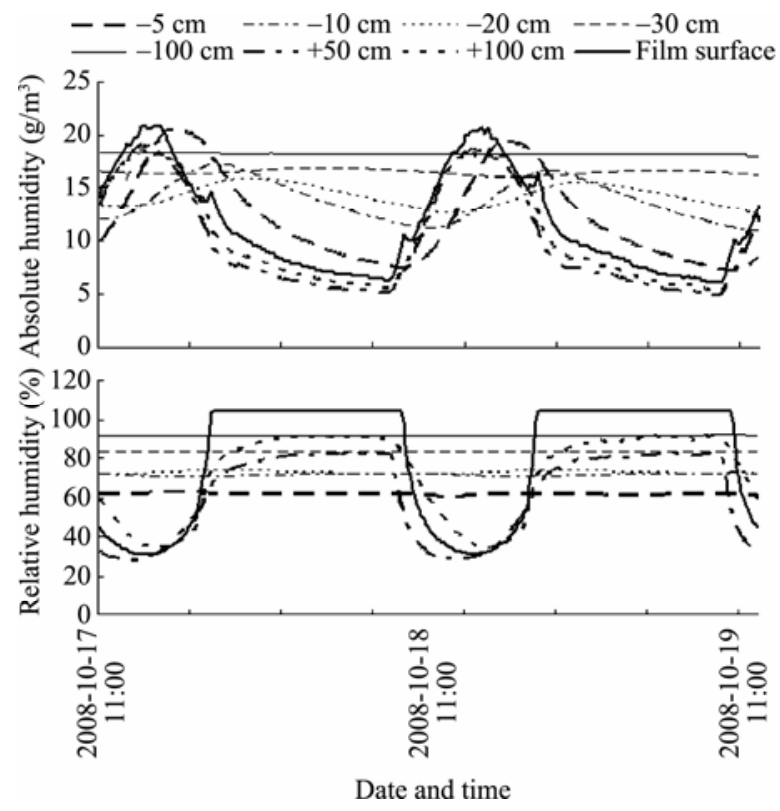

Fig. 6 Relative humidity and absolute humidity in the greenhouse at different heights above ground surface and depths of soil

absorbed by soil when the temperature declines (Fig. 4). This phenomenon reflects the typical characteristic 
of bound water in extremely arid area. At the deeper soil layer in which the daily fluctuation of temperature is small, and the soil humidity is stable.

Figure 7 shows that the relative and absolute humidity of outside soil were apparently lower than that in the greenhouse (Fig. 6), which indicated the greenhouse could not only increase temperature but also soil humidity. According to the humidity/temperature condition for water migration (Zhu and Qian, 2005; Warner, 2008), the soil water in the greenhouse can move outward and the water inside is not from outside soil or air when the air temperature, relative and absolute humidity inside and outside greenhouse were similar, which meets the condition of the upper migration of water. Because vapour migration flux is correlative to the gradient of air humidity, the dry air outside greenhouse determines outward movement of soil water. This illustrates that evaporation is not limited in the "heat island" greenhouse but exists widely. Our former weighing experiment of the soil samples outside greenhouse conformed this phenomenon ( $\mathrm{Li}$ et al., 2010a).

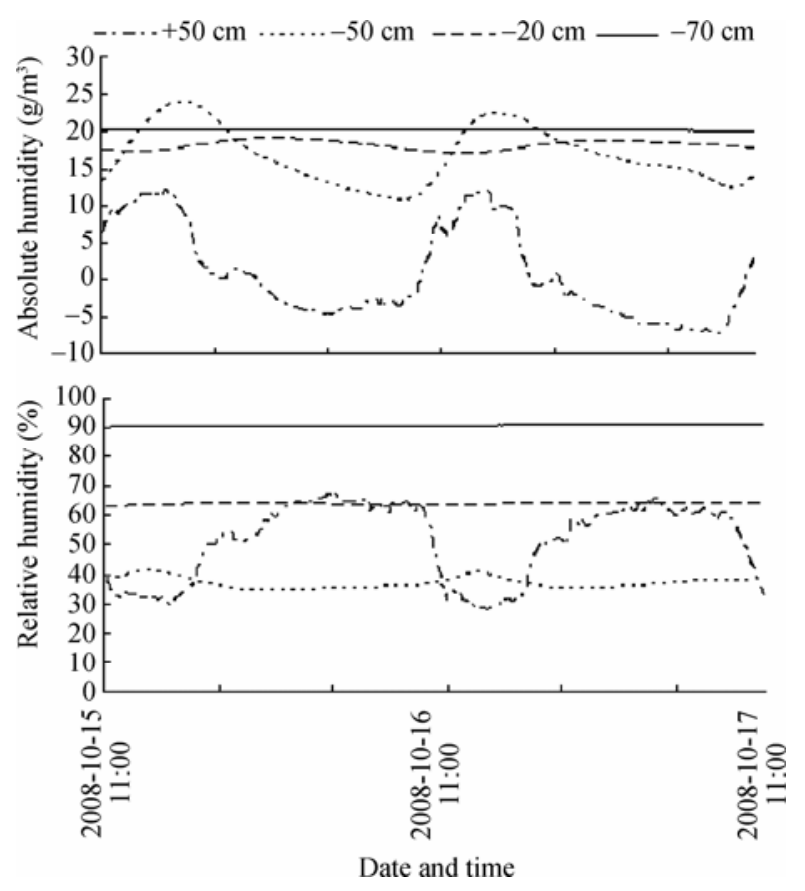

Fig. 7 Relative humidity and absolute humidity at different depths outside greenhouse

The decomposition and combination of soil water is a dynamical process driven by varying temperature.
When the soil temperature increased, the soil water evaporation led to an evident increase of vapour density in the greenhouse; while the temperatures of air and top-soil decrease, water would be absorbed by soil particle and salt, and the vapour density declines too. The soil evaporates water in warming process and absorbs water in cooling process in afternoon, which forms the "respiration" of soil (Zhang and Wei, 2003).

\subsection{The influence of phreatic water, salt and geo- thermy on soil water}

The random monitoring results of soil water contents in 2007 and 2008 are shown in Fig. 8. The average contents of soil water are nearly the same. However, the soil water content at $20 \mathrm{~cm}$ depth is higher than that at other depths. This implies that although soil water contents were fluctuated with climate and daily temperature, they were stable as a whole and did not decrease unlimitedly due to continuing evaporation, which indicated the existence of deep water.

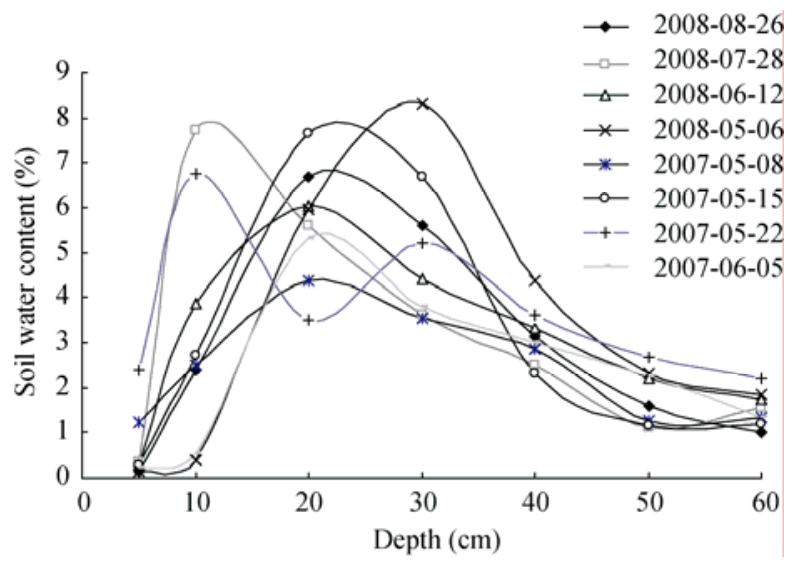

Fig. 8 The soil water distribution in representative days in the extremely dry area

The abundant salt content in top soil layer is another proof to the existence of phreatic water. The preliminary monitoring results revealed that in the aeration zone at $2.9 \mathrm{~m}$ depth the relative humidity of soil was saturated. An observation at $1.25 \mathrm{~m}$ depth of surrounding rocks at the Grottoes indicated that the humidity in deep rock is perennially saturated (Guo et al., 2009). This shows that the aeration zone below $2.9 \mathrm{~m}$ depth is saturated. The formation of the saturated vapour is caused by geothermy. Affected by geothermy, the temperature of soil from bottom to top decreases 
with a rate of $2-3^{\circ} \mathrm{C}$ per $100 \mathrm{~m}$. Normally, the heat transmitted by geothermy is $2 \times 10^{7} \mathrm{~J} / \mathrm{m}^{2}$ (Liu and Cai, 2000). In this area there is a fracture belt of Sanwei Mountain and the large quantity of geothermic energy has been already found. Based on the temperature of hot well which is $50-60^{\circ} \mathrm{C}$ at $1,100-1,500 \mathrm{~m}$ depth, the temperature gradient in this area is around $3-4^{\circ} \mathrm{C}$ per $100 \mathrm{~m}$.

The saturated vapour in aeration zone could condense and form film water on the surface of gravel sand under a reducing gradient of temperature. Dissolved salt in the film water migrates upward slowly and stays in an evaporating surface of soil at about 20 cm depth (Zhu and Qian, 2005). After a long geology duration a saline soil layer about $50 \mathrm{~cm}$ thickness was formed and acicular crystals were found in soil profile (Li et al., 2009; Yang et al., 2009). The high soil water content at the clay layer was the concentration of film water for soil particles with strong absorbing ability. The evaporation of vapour in unsaturated zone improves the salt density gradient in film water and the water potential difference, as well as the upward migration ability of film water. Dry climate helps to form a big humidity gradient in unsaturated belt; and also forms a dynamic factor for the upward migration of deep water. The high humidity and porosity (20\%-30\%) of deep soil are necessary to continued vertical movement of vapour. Vapour and film water are the two main forms of phreatic water movement and the two phases coexist but also shift each other when temperature changes.

Salt is a key factor that influences soil water content. Salts such as $\mathrm{Na}_{2} \mathrm{SO}_{4} \cdot 10 \mathrm{H}_{2} \mathrm{O}, \mathrm{MgSO}_{4} \cdot 7 \mathrm{H}_{2} \mathrm{O}$, $\mathrm{MgCl}_{2} \cdot 6 \mathrm{H}_{2} \mathrm{O}$ and $\mathrm{Na}_{2} \mathrm{CO}_{3} \cdot 10 \mathrm{H}_{2} \mathrm{O}$ significantly enhance the soil water content at upper layer $(10-40 \mathrm{~cm})$. $\mathrm{Na}_{2} \mathrm{SO}_{4}$ is abundant at $10-30 \mathrm{~cm}$ soil depth and when temperature is lower than $32.5^{\circ} \mathrm{C}, \mathrm{Na}_{2} \mathrm{SO}_{4}$ combines with water and then forms $\mathrm{Na}_{2} \mathrm{SO}_{4} \cdot 10 \mathrm{H}_{2} \mathrm{O}$, which triggers the notably increase of soil water content and vice versa ( $\mathrm{Li}$, 2005; Angeli et al., 2007). In summer, the soil temperature in the greenhouse was higher than $32.5^{\circ} \mathrm{C}$, thus the soil water content at $20 \mathrm{~cm}$ depth was lower than that at the control sample outside (Fig. 9 a and $b$ ).

In summer, the soil water content at $20 \mathrm{~cm}$ depth was $4 \%$ lower than that at the control one, and the decrement of soil water was similar to that of condensed water amount. If the change of soil water was not caused by temperature and salt, the condensed water could only come from soil moisture and there was
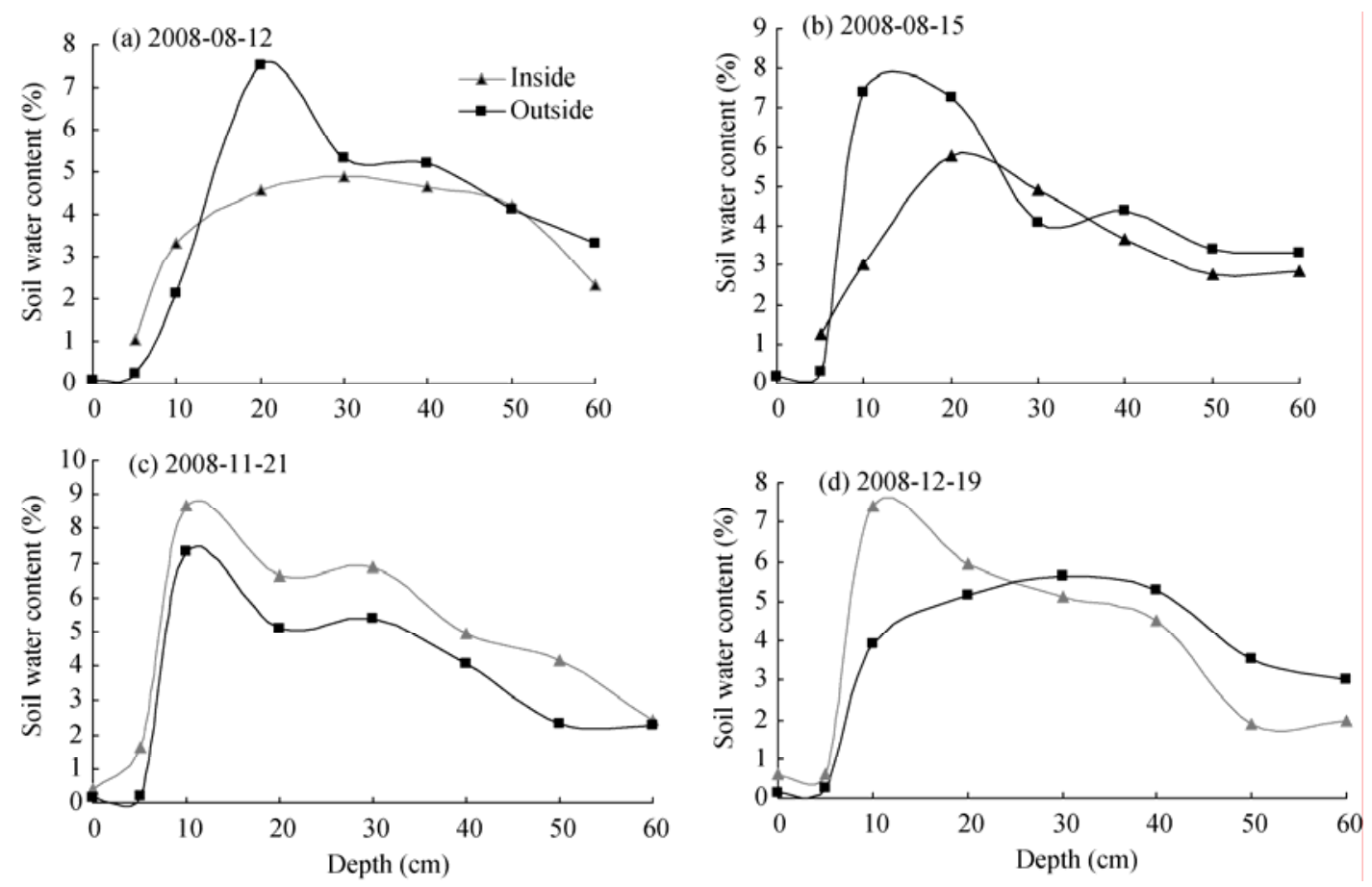

Fig. 9 Comparison of soil water contents inside and outside greenhouse 
no upward migration of phreatic water. Under this condition, to confirm the existence of deep water migration, humidity in the soil of greenhouse should be equal to or higher than the control one when temperature was lower than the critical value of $32.5^{\circ} \mathrm{C}$. Monitoring of soil temperature in winter identified that soil water content was high when soil temperature was lower than $32.5^{\circ} \mathrm{C}$. The soil water content at $20 \mathrm{~cm}$ depth was higher than that at the control one and that at the early days after building of greenhouse. This result confirms the existence of deep water migration, and denies the possibility that the decrease of isolated soil water was caused by soil structure damage. Another experiment at the same period verified that condensed water in the greenhouse was not derived from outer air or precipitation (Li et al., 2010a). Therefore, the condensed water in the greenhouse was surely from the deep soil.

Furthermore, another greenhouse experiment from $1 \mathrm{~km}$ distance demonstrates that continuous water condensed also existed in the sandy land (Li et al., 2010b), indicating that our research setting is reasonable. In addition, we did an experiment with an air-condition inside the greenhouse to restrain the "greenhouse effect" and the evaporation of phreatic water reached up to $21.9 \mathrm{~g} /\left(\mathrm{m}^{2} \cdot \mathrm{d}\right)$ (10 times of this one), which further confirms our analysis (Li et al., 2010c). In conclusion, the condition and mechanism for the upward migration of phreatic water exist where groundwater level is deeply buried, and the ultimate resource of deep soil water is no other than phreatic water. Phreatic water evaporation is widespread in extremely arid area.

\section{Conclusions}

The results of the greenhouse experiment above Mogao Grottoes at the gobi land under typical dry climate condition showed that phreatic water evaporation exists in the extremely dry area where ground

\section{References}

Angeli M, Bigas J P, Benavente D. 2007. Salt crystallization in pores: quantification and estimation of damage. Environmental Geology, 52: 205-213.

Chen M J, Wang H, Wang F. 2004. Water-driver ecological evolution mechanism in inland arid region. Acta Ecological Sinica, 24 (10): water is deeply buried, and soil water could enter atmosphere through aeration zone. The temperature, relative and absolute humidity at the deep soil layer were higher than that of the upper soil layer, and this condition is suitable to the upward migration of phreatic water. Even in summer when the temperature of the top-soil was higher, the humidity gradient at the sub-layer was enough to support the constant migration and evaporation of phreatic water. In a warming process soil bound water was decomposed and evaporated, and it was absorbed by soil when temperature decreased. The soil temperature change is a key to the fluctuation of soil water and exchange of air moisture. Thermo-dynamical effect is fundamental to the vertical movement of water in GSPAC system. Dry climate, geothermy and soil salt all play important roles in the migration, spatial and temporal distribution of soil water. The increasing of soil water content after a long-term experiment reflects that phreatic water evaporation can occur at different burial depths. Impacted by the closed environment, the condensed water amount on the film was not the actual evaporation of natural soil, and the transported phreatic water in this extremely arid area should be more than measured one. The discovery of phreatic water evaporation in extremely dry area and its related analysis provide new possibility of ecological restoration using water in the GSPAC system. Meanwhile, understanding the water resource in the surrounding rocks of Mogao Grottoes at a large scale is of great importance to the conservation work of culture relics in the Grottoes.

\section{Acknowledgements}

This work was founded by the National Natural Science Foundation of China (40940005). The authors thank Mr. Fei QIU, HongTao ZHAN, ShuangHu LING and Rui LI for their sincerely help in field work; we also thank our fellows in the environmental research group for their support of meteorological data.

2108-2114.

Guo Q L, Wang X D, Xue P. 2009. Research on spatial distribution and relations of salinity and moisture content inside rock mass of low-layer caves in Dunhuang Mogao Grottoes. Chinese Journal of Rock Mechanics and Engineering, 28 (Suppl. 2): 3769-3776. 
Li H S, Wang W F, Guo Q L. 2009. Mechanism analysis on water cohesion in arid area of Dunhuang Mogao Grottoes. Acta Ecologica Sinica, 29 (6): 3198-3205.

Li H S, Wang W F, Zhan H T. 2010a. New judgement on the source of soil water in extremely dry zone. Acta Ecologica Sinica, 30 (1): 1-7.

Li H S, Wang W F, Zhang G B. 2010b. Qualitative analysis on the water source of dune by coved canopy method in the extreme dry area. Journal of Desert Research, 30 (1): 97-103.

Li H S, Wang W F, Zhang G B. 2010c. Measurement of deep buried phreatic water evaporation in extremely arid area. Acta Ecologica Sinica, 30(4): 6798-6803.

Li Z X. 2005. Conservation of the Wall Paintings and Colored Statues of the Grottoes on the Silk Road. Beijing: Science Press, 360-371.

Liu B P, Cai Y L. 2000. An Introduction to Earth Science. Beijing: Higher Education Press, 4, 79.

Liu X P, Zhang T H, Zhao H L. 2006. Infiltration and redistribution process of rainfall in desert mobile sand dune. Journal of Hydraulic Engineering, 37 (2): 166-171.

Ren J, Shi H B, Li H P. 2006. Study on water dynamics of GSPAC system over Maowusu sandland in Etuoke Banner. Journal of Irriga- tion, 25 (3): 23-26.

Wang X S, Yue W F, Yang J Z. 2004. Analysis on water cycling in GSPAC system of Tetao-irigation district, in Inner Mongolia, China. Journal of Irrigation and Drainage, 23(2): 30-33.

Warner T T. 2008. Desert Meteorology. Beijing: China Meteorology Press, 136-153.

Yang J F, 1999. A review on water exchange through interface between groundwater, soil moisture or atmospheric water. Advance in Water Science, 10 (2): 184-190.

Yang S L, Wang X D, Guo Q L. 2009. Preliminary analysis of moisture distribution in cliff rocks of the Mogao Grottoes in Dunhuang. Hydrogeology and Engineering Geology, 5: 94-97.

Zhang Q, Wei G A. 2003. Analysis of inverse humidity respiration process of surface soil in desert near oasis. Journal of Desert Research, 23 (4): 379-384.

Zhou A G, Ma R, Zhang C. 2005. Vertical water cycle and its ecological effect in inland basins, Nowthwest China. Advances in Water Science, 16(1): 127-133.

Zhu X Y, Qian X X. 2005. Groudwater Hydrology. Beijing: China Environmental Sciences Press, 83.

\section{Journal of Arid Land was included in Abstract Journal, All-Russian Institute of Scientific and Technical Information (VINITI) Database}

On December 22, 2010, an E-mail by Dr. Elena Raevskaya, the manager of Asia and Africa Section, All-Russian Institute of Scientific and Technical Information (VINITI), was sent to Journal Publishing Center, Xinjiang Institute of Ecology and Geography, CAS and said "Here is some new information about the Chinese journals evaluated by our experts. Ten journals have been found informative and useful in our work and have been included in VINITI database for regular abstraction (some of these journals were reexamined by expertise).”

The VINIT publishes Abstract Journal, which has been issued since 1953. Abstract Journal is divided into 3 types, integration, single-volume and fascicule, embodying total 220,000 journals and over 6,000 serials in 66 languages from 130 countries and regions, and over 10,000 books, and 150,000 monographs and scientific and technologic reports each year, which cover all fields of natural and applied sciences. AJ is an authentic abstracting database with the most numbers of citing publication and reporting.

AJ assessment to journals is very strict. In 2007, AJ published a list of Chinese journals which was excluded, and 28 Chinese scientific journals were in the list. In this time, 6 Chinese journals were excluded.

Journal of Arid Land applied the assessment to AJ since the Journal was launched at the end of 2009 and was included in the database after the Journal was strictly evaluated. 